\title{
3D Visualization of Bamboo Node's Vascular Bundle
}

\author{
Shan Li ${ }^{1,2}$, Shumin Yang ${ }^{1, * \mathbb{C}}$, Lili Shang ${ }^{1} \mathbb{C}$, Xinge Liu ${ }^{1}$, Jianfeng Ma ${ }^{1}$, Qianli Ma ${ }^{1}$ and Genlin Tian ${ }^{1}$ \\ 1 International Center for Bamboo and Rattan, Key Laboratory of National Forestry and Grassland \\ Administration, Beijing 100102, China; shanli6758@163.com (S.L.); shangll@icbr.ac.cn (L.S.); \\ liuxinge@icbr.ac.cn (X.L.); Majf@icbr.ac.cn (J.M.); maqianli@icbr.ac.cn (Q.M.); tiangenlin@icbr.ac.cn (G.T.) \\ 2 College of Forestry, Sichuan Agricultural University, Chengdu 611130, China \\ * Correspondence: yangsm@icbr.ac.cn
}

Citation: Li, S.; Yang, S.; Shang, L.; Liu, X.; Ma, J.; Ma, Q.; Tian, G. 3D Visualization of Bamboo Node's Vascular Bundle. Forests 2021, 12, 1799. https://doi.org/10.3390/ f12121799

Academic Editor: Kei'ichi Baba

Received: 29 November 2021

Accepted: 13 December 2021

Published: 17 December 2021

Publisher's Note: MDPI stays neutral with regard to jurisdictional claims in published maps and institutional affiliations.

Copyright: (c) 2021 by the authors. Licensee MDPI, Basel, Switzerland. This article is an open access article distributed under the terms and conditions of the Creative Commons Attribution (CC BY) license (https:// creativecommons.org/licenses/by/ $4.0 /)$.

\begin{abstract}
The vascular bundle is an important structural unit that determines the growth and properties of bamboo. A high-resolution X-ray microtomography $(\mu \mathrm{CT})$ was used to observe and reconstruct a three-dimensional (3D) morphometry model of the vascular bundle of the Qiongzhuea tumidinoda node due to its advantages of quick, nondestructive, and accurate testing of plant internal structure. The results showed that the morphology of vascular bundles varied significantly in the axial direction. In the cross-section, the number of axial vascular bundles reached a maximum at the lower end of the sheath scar, and the minimum of it was at the middle of the diaphragm. The frequency of axial vascular bundles decreased from the lower end of the node to the nodal ridge, and subsequently increased until the upper end of the bamboo node. The proportion of parenchyma, fibers, and conducting tissue was $65.7 \%, 30.5 \%$, and $3.8 \%$, respectively. The conducting tissues were intertwined to form a complex 3D network structure, with a connectivity of $94.77 \%$. The conducting tissue with the largest volume accounted for $60.26 \%$ of the total volume of the conducting tissue. The 3D-distribution pattern of the conducting tissue of the node and that of the fibers were similar, but their thickness changed in the opposite pattern. This study revealed the 3D morphometry of the conducting tissue and fibers of the bamboo node, the reconstruction of the skeleton made the morphology more intuitive. Quantitative indicators such as the 3D volume, proportion, and connectivity of each type of tissue was obtained, the bamboo node was enlarged mainly caused by the particularly developed fibers. This work laid the foundation for a better understanding of the mechanical properties and water transportation of bamboo and revealed the mystery of bamboo node shedding of $Q$. tumidinoda.
\end{abstract}

Keywords: Qiongzhuea tumidinoda; structure of bamboo node; three-dimensional reconstruction; vascular bundle; $X$-ray microtomography

\section{Introduction}

The node is the basic characteristic of bamboo plants and plays a key role in the overall performance of the hollow structure of bamboo culms [1,2]. The vascular bundle serves as a mechanical support to improve the mechanical properties of bamboo [2,3] and perform the function of transporting water and nutrients [4]. Numerous reports are available on the microstructure of the bamboo culm, mainly on the internodes [5-7]. However, the research concerning the structure of bamboo nodes due to its disordered and relatively complicated arrangement of vascular bundles is limited. The research on the structure of bamboo nodes began in the 1960s [8] and mainly relied on optical microscopes. In the late 20th century, the researches related to the anatomy of bamboo nodes gradually increased [4,9-11]. Grossor and Liese [11] studied the characteristics of vascular bundles of bamboo nodes through enlarged and spliced images of microsections. Xiong et al. studied the shape of bamboo nodes and conducted a preliminary discussion on the 3D characteristics of vascular bundles [10,12]. Ding and Liese [4] reconstructed a complex 3D structure of vascular bundles of bamboo nodes by observing continuous longitudinal 
and transverse slices. Currently, the research of the bamboo microstructure mainly relies on two-dimensional (2D) image characterization techniques such as optical microscope and field emission scanning electron microscope. However, the aforementioned methods damaged the samples, leading to the inaccurate results. The complexity and fragility of sample preparation with traditional techniques make it difficult to meet the requirements of nondestructive, high-efficiency visualization. Therefore, a higher-resolution nondestructive testing method is needed.

With the continuous development of research methods, X-ray microscopy has strong penetrating power, high resolution, and nondestructive property, resulting in fast detection and intuitive results, and indicating advantages of bamboo node analysis. Peng et al. [13] and Xiang et al. [14] used X-ray microtomography $(\mu \mathrm{CT})$ as a tool for 2D and 3D complex network structures of the vascular bundle in the bamboo node. Huang et al. quantified the difference in the density distribution and the porosity of bamboo nodes based on 2D images [15,16]. Palombinifl et al. [17-19] analyzed the relative density and cell shape of different tissues of a cutting region of bamboo nodes, evaluated the mechanical behavior of parenchyma by finite element analysis, and first obtained the 3D reconstruction model of the complex vascular bundle system of monocot nodes. The volume, porosity, relative density, and distribution of nodes were also characterized. The aforementioned research by X-ray technique had two limitations: (1) The conducting tissue and the fibers of the completed node's vascular bundle were not separated to separately observe the morphology of them. (2) The complex distribution of transverse vascular bundles in the diaphragm was neglected.

Qiongzhuea tumidinoda Hsueh et T.P.Yi. belongs to the genus Qiongzhuea in the Gramineae family, with an enlarged node and a peculiar-shaped culm. The species reaches approximately $2.5-6 \mathrm{~m}$ in height, and its culm reaches $1-3 \mathrm{~cm}$ in diameter. $Q$. tumidinoda, only found in a restricted area in S.W. Sichuan and N.E. Yunnan, is a rare and endangered bamboo species, which is a Class 3 protected plant on the national key protection list in China. Among them, especially in Daguan County, Yunnan province, this bamboo accounts for more than $50 \%$ of the total global resources, with 0.014 million hectares. The bamboo culm is mainly used for crafts and production of round bamboo furniture with extremely high economic and ornamental value. However, this bamboo at more than 5-years of age will gradually begin to wither and die. The most obvious feature is that the node automatically disconnects. Furthermore, the culm is more prone to regular fracture at the nodal ridge of the node, even less than 5-year-old bamboo. The presence of the bamboo node makes it possible for the lateral transport of water and nutrients [4], and there is little research on what happened to its structure before the node fell off. This study aims to obtain the complete $Q$. tumidinoda node internal structure quickly, nondestructively, and accurately by high-resolution $\mu \mathrm{CT}$, to reconstruct the 3D model of conducting tissue and fibers of the node and to explore complex distribution of transverse vascular bundles in the diaphragm of the node. The study results will provide the basis for revealing the mystery of bamboo node shedding of $Q$. tumidinoda.

\section{Materials and Methods}

\subsection{Materials}

Five 2-year-old $Q$. tumidinoda bamboo plants with good growth and straight stems were collected from Yinji Village, Daguan County, Yunnan Province $\left(103^{\circ} 99^{\prime} \mathrm{N}, 28^{\circ} 13^{\prime} \mathrm{E}\right)$. The culm was cut every $2 \mathrm{~m}$ from the base to the top of it, marked, and transported to the laboratory. After natural air drying, complete bamboo nodes with 5.74\% moisture content from the middle of the culm were selected (Figure 1b) and were ready to be used for the subsequent experiments. The selected node was approximately $1.83 \mathrm{~m}$ of the culm, which was $3.7 \mathrm{~m}$ in height and $1.2 \mathrm{~cm}$ in diameter. 


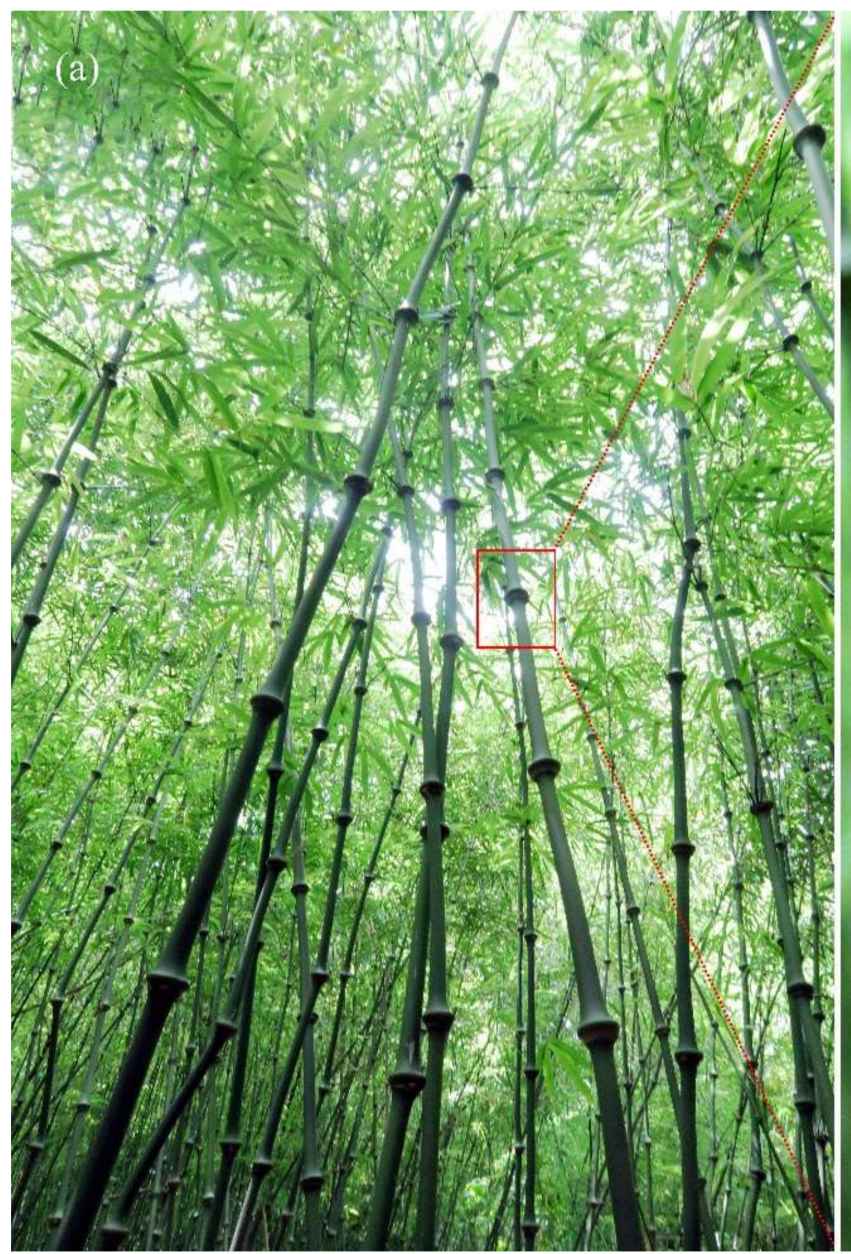

Figure 1. Preparation of $\mu \mathrm{CT}$ sample. (a) Bamboo.

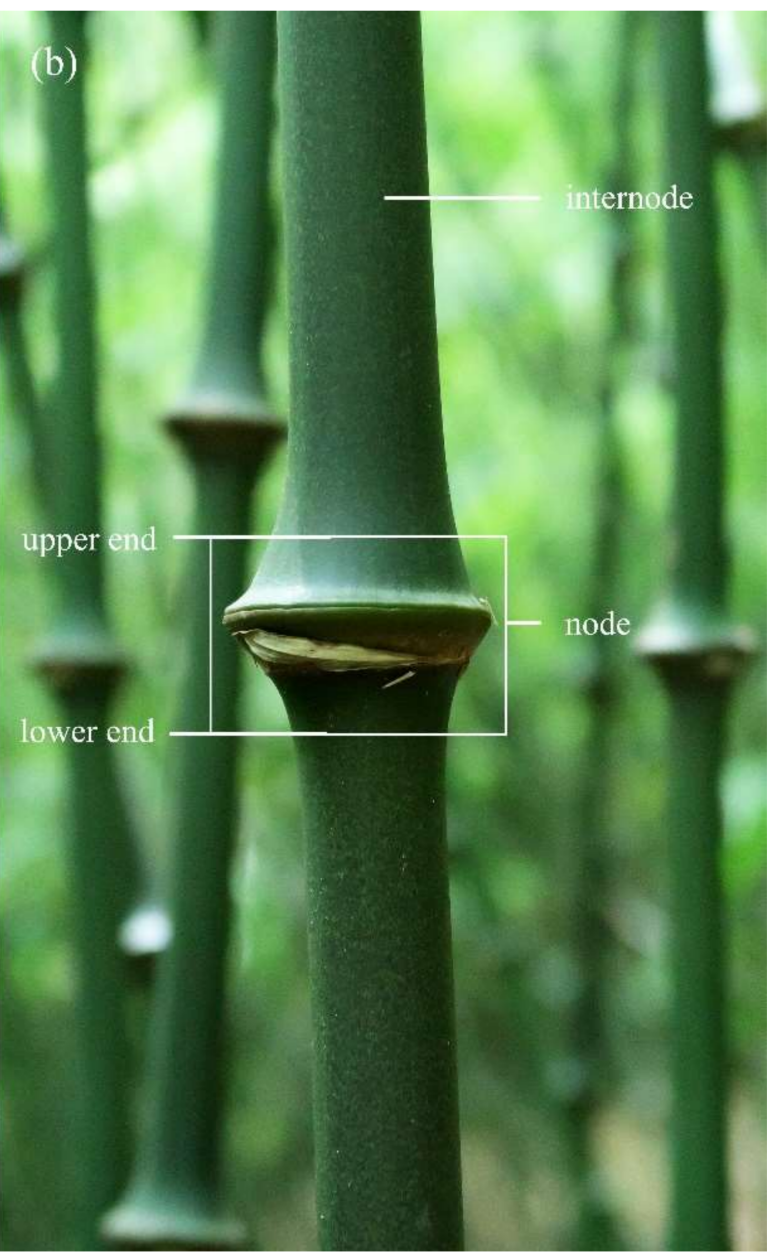

(b) Sampling location (white wireframe area).

\subsection{CT Scanning}

The samples were scanned by the X-ray high-resolution imaging system (Skyscan2214, Bruker, MA, USA). The test parameters were set as follows: the X-ray source voltage of $50 \mathrm{kV}$, tube current of $90 \mu \mathrm{A}$, power of $1.14 \mathrm{~W}$, and resolution of $10 \mu \mathrm{m}$ after binning the source-sample distance of $42.8 \mathrm{~mm}$ and source-detector distance of $320.5 \mathrm{~mm}$. The sample was placed vertically on the sample table, the scanning position was $8.56 \mathrm{~mm}$. A total of 3601 projections with an angular step size of $0.1^{\circ}$ were obtained with exposure time of $750 \mathrm{~ms}$, resulting in a total acquisition time of $10 \mathrm{~h} 6 \mathrm{~min}$.

\subsection{Image Processing and 3D Reconstruction}

Images were processed and analyzed with the open-source Fiji software (National Institutes of Health, Bethesda, MD, USA) and the AVIZO software (FEI Hillsboro, OR, USA), the processing steps are shown in Figure 2. The slices were combined and reconstructed from the projections with a noniterative filtered backprojection algorithm in NRecon software and then exported as a stack of TIFF images. A total of 1290 slices with serial numbers 329-1618 were obtained. The original TIFF stack (Figure 2a) was first denoised with the adaptive median filtering technique combined with the non-local mean filtering algorithm (Figure 2b), and the contrast was adjusted (Figure 2c). Figure 2a1,b1,c1 demonstrates details of the same slice before and after noise reduction and contrast adjustment, respectively. The denoised intensity images had clear boundaries for easy segmentation. 

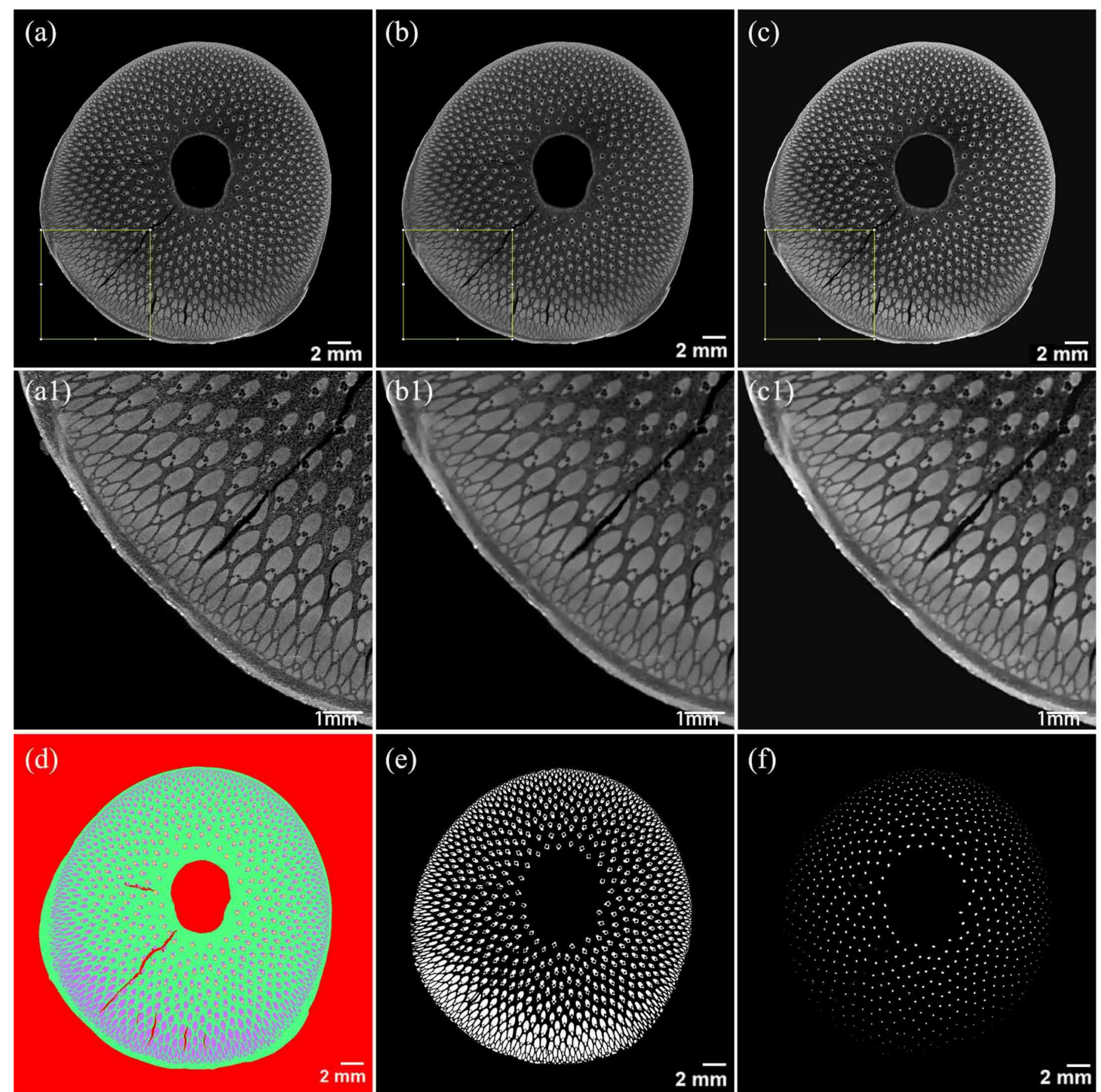

Figure 2. Image processing of $\mu \mathrm{CT}$. (a) Original $\mu \mathrm{CT}$ slice and its details (a1). (b) Filter processing and its details (b1). (c) Contrast adjusting and its details (c1). (d) Segmentation of the conducting tissue (yellow), fibers (purple), parenchyma (green), and air (red). (e) Binary images of fibers. (f) Binary images of conducting tissue.

For a better visualization in addition to automatic recognition of different tissues in the nodal region using the machine learning segmentation plug-in [20] in ImageJ (FIJI is just ImageJ), the mask of each tissue type with threshold segmentation were corrected manually to obtain binarized images of fibers and conducting tissues (Figure 2e,f). At last, the AVIZO software was used to generate the skeleton and the surface mesh of fibers and conducting tissue. The skeleton was obtained by calculating a distance map of the segmented image and then by thinning the binary image such that a final string of connected voxels remained. The voxel skeleton was then converted into a Spatial Graph object. The distance to the nearest boundary was stored at every point in the Spatial Graph object as a thickness attribute [21]. The surface mesh model was used to generate a smoother surface to compensate for the information loss caused by the resampling process [22]. Some slices (slice 339, slice 387 , slice 579 , slice 669 , slice 849 , slice 944 , slice 1129 , slice 1429) appeared as new and particular features relative to its bottom slice, which were used for observing the morphology of them. 


\subsection{Statistical Analysis}

The size of axial vascular bundles was acquired through ImageJ by measuring the axial vascular bundles in the marquees $\left(1.5 \times 28 \mathrm{~mm}^{2}, 28 \times 1.5 \mathrm{~mm}^{2}\right)$, which was in the shape of a cross and was created on each slice that is used for morphological observation. The statistical number of vascular bundle sizes ranged from 74 to 142, and the significant analysis of variance axial vascular bundle's size was carried out with Duncan's test, which was measured by the software IBM SPSS Statistics 19. The number of axial vascular bundles was determined by counting one slice out of every 85 slices from the bottom to the top of samples, and 16 sets of data were collected using cell counter of ImageJ software. The area, proportion, and volume of each type of tissue in the bamboo node were obtained by the AVIZO software. The results were statistically analyzed and graphed by Origin 2018.

\section{Results and Discussion}

\subsection{Morphology of the Bamboo Node}

The morphological diagram of the node of Q. tumidinoda is shown in Figure 3a, which consists of a sheath scar, nodal ridge, diaphragm, and the intra-node between the nodal ridge and sheath scar. The rare swollen node was seen in Q. tumidinoda bamboo, the nodal ridge was more swollen than the sheath scar. This might be related to the different speeds of cell division and growth around the intercalary meristem [12].
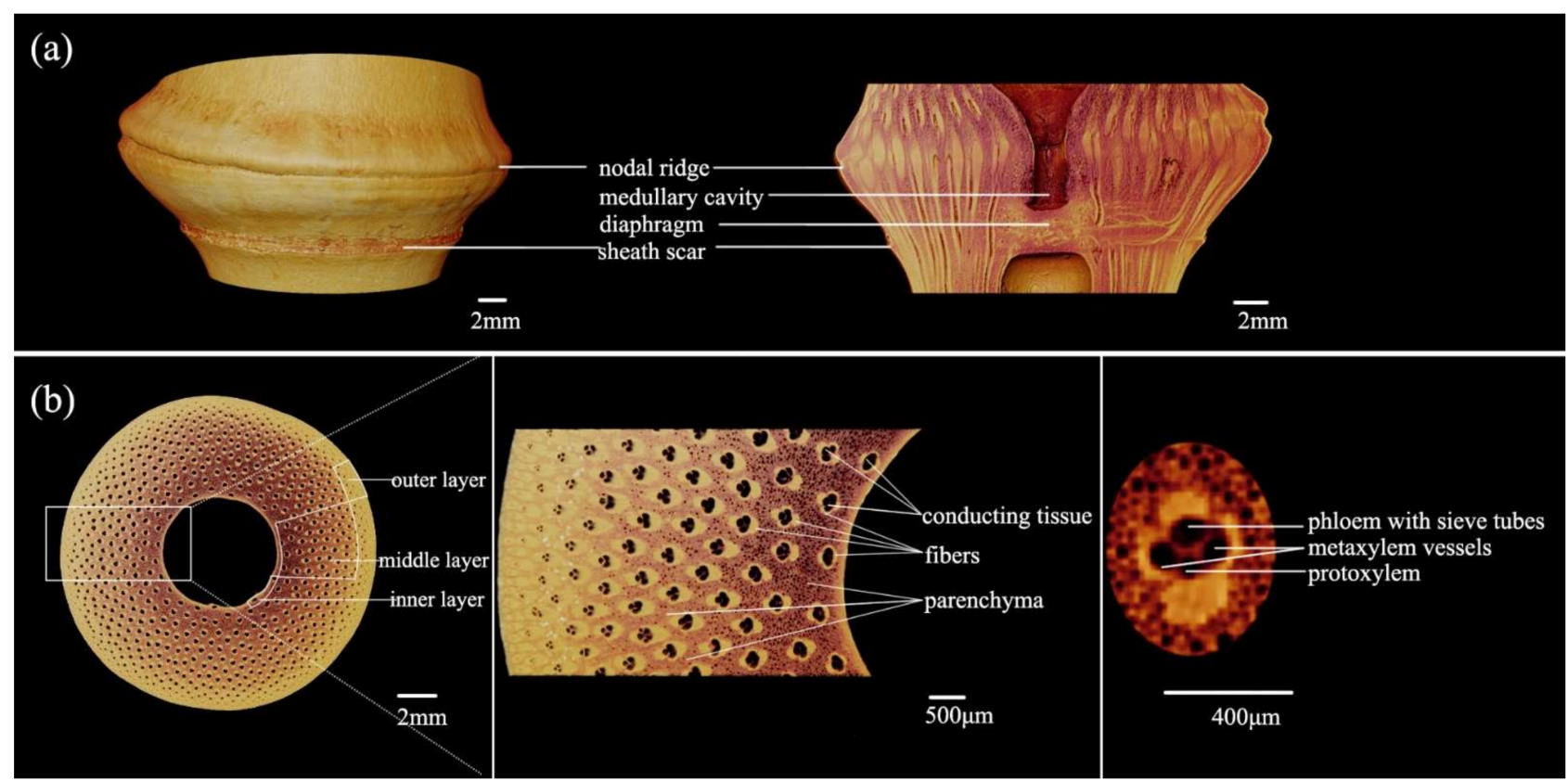

Figure 3. Morphology of the node in Q. tumidinoda. (a) Longitudinal section view. (b) Cross-section and details.

The cross-section of bamboo was divided into the following three parts according to the position in the bamboo culm: outer layer, middle layer, and inner layer (Figure 3b). It was also classified into parenchyma, fibers, and conducting tissue (metaxylem vessels, phloem with sieve tubes, protoxylem) by tissue type. The vascular bundle was mainly composed of conducting tissue and fibers. The conducting tissue transported water and nutrients from the roots to different parts of the bamboo. The fibers were relatively hard and provided mechanical support, while the parenchyma with a thin cell wall served as a reservoir and a buffer, they cooperated to enhance the elasticity of the bamboo culm [23].

No other solid part was observed in the nodal area except in the diaphragm from the cross-sectional view of a bamboo node with different heights (Figure 4a1-h1). Only the diaphragm was solid in the node, indicating disagreement with the previous results [24] and that the solid area appeared repeatedly in the node of Q. tumidinoda. This might be caused by the difference in the environment and position of the culm. 


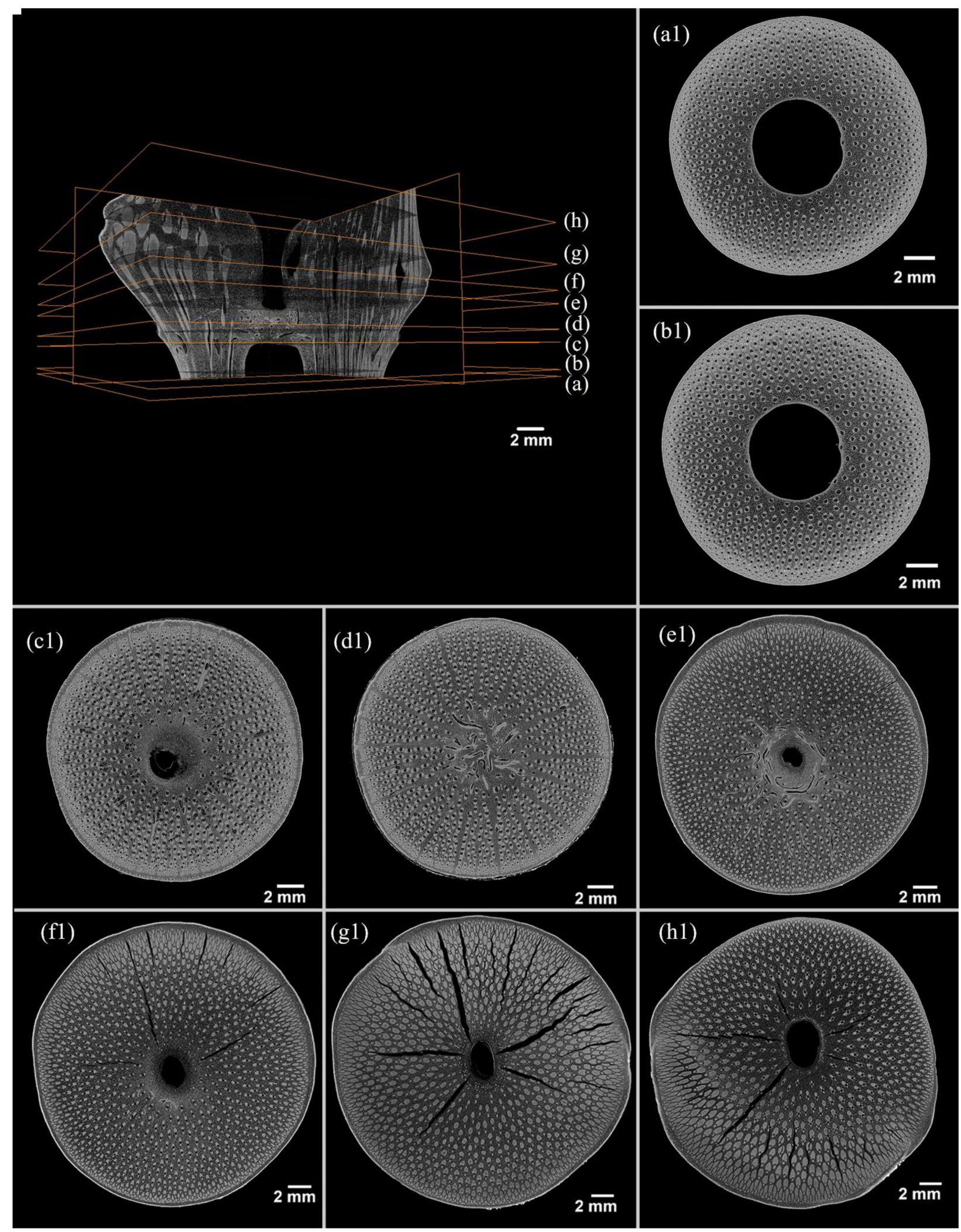

Figure 4. X-ray microtomography slices of the Q. tumidinoda node. The sequence number of the transversal slices is 329-1618 from the lower end to the upper end (details of $\mathbf{a}-\mathbf{h}$ present in a1-h1). (a1) Slice 339, end of the node. (b1) Slice 387, lower end of the node. (c1) Slice 579, lower end of the sheath scar. (d1) Slice 669, middle of the diaphragm. (e1) Slice 849, upper end of the diaphragm. (f1) Slice 944, lower end of the nodal ridge. (g1) Slice 1129, middle of the nodal ridge, and (h1) Slice 1429 , upper end of the nodal ridge. 


\subsection{Anatomical Characteristics of Vascular Bundles in Bamboo Nodes}

\subsubsection{Morphological Changes in Vascular Bundles}

The images of slices showing anatomical features at different heights (Figure 4a1-h1) were enlarged to obtain Figure $5 \mathrm{~A}-\mathrm{H}$, in order to determine the structural changes in the vascular bundles in bamboo nodes along the axial direction. The morphology of the vascular bundle changed obviously in the axial direction. The lateral and inner fiber sheath of the vascular bundle was connected in the lower slice, called as semi-open type [23] (Figure 5A, green arrow; Figure 5B, green arrow). Along the axial height direction to slice 387 , the morphology of the vascular bundle changed, and the conducting tissue enlarged and deformed (Figure 5A, red arrow; Figure 5B, red arrow).

At the lower end of the sheath scar, the diaphragm appeared (Figure 5C, red arrow), with a large amount of irregularly shaped conducting tissue around the diaphragm (Figure 5C, green arrow). The outer fiber sheath of the axial vascular bundle was enlarged at the lower end of the diaphragm, with a large number of undifferentiated vascular bundles into the cortex (Figure 5C, blue arrow). The transverse vascular bundles were concentrated in the middle of the diaphragm (Figure 5D), which was consistent with the results of the study by Peng and Ding [4,13]. The lateral fiber sheaths of the axial vascular bundles were weakly developed or even disappeared, while the inner and outer fiber sheaths were extremely developed. The orientation of the long axis of the axial vascular bundles changed near the diaphragm, and the inner and outer fiber sheaths of the vascular bundle were distributed in a tangential direction (Figure 5D, yellow arrow). In previous studies, it was believed that the incorrect expression of gene transcription factors would cause the reversed polarity of the vascular bundles [25].

At the upper end of the diaphragm, the medullary cavity appeared again (Figure 5E, blue arrow), with many transverse vascular bundles. This result was different from the conclusion of Peng [13], which revealed no transverse tubules when the medullary cavity of the node of Pleioblastus gozadakensis appeared (Figure 5E, yellow arrow). At the lower end of the nodal ridge, the transverse vascular bundle within the node almost disappeared (Figure 5F, blue arrow). This result was inconsistent with Ding's previous research, in which the transverse vascular bundles disappeared above the nodal ridge [4]. No vascular bundles were present in the nodal ridge, and some high-density materials appeared (Figure 5F, yellow arrow), which might be highly lignified sclereid layers [10].

In the middle of the nodal ridge, the transverse vascular bundles completely disappeared, the conducting tissue became smaller, the inner fiber sheath was enlarged, and the outer fiber sheath was significantly smaller than the inner fiber sheath. A large amount of high-density material (increased whiteness) appeared in the nodal ridge (5G, blue arrow). At the upper end of the nodal ridge, the type of vascular bundle ranged from semi-open (Figure $5 \mathrm{H}$, blue arrow) to open (Figure $5 \mathrm{H}$, yellow arrow). 

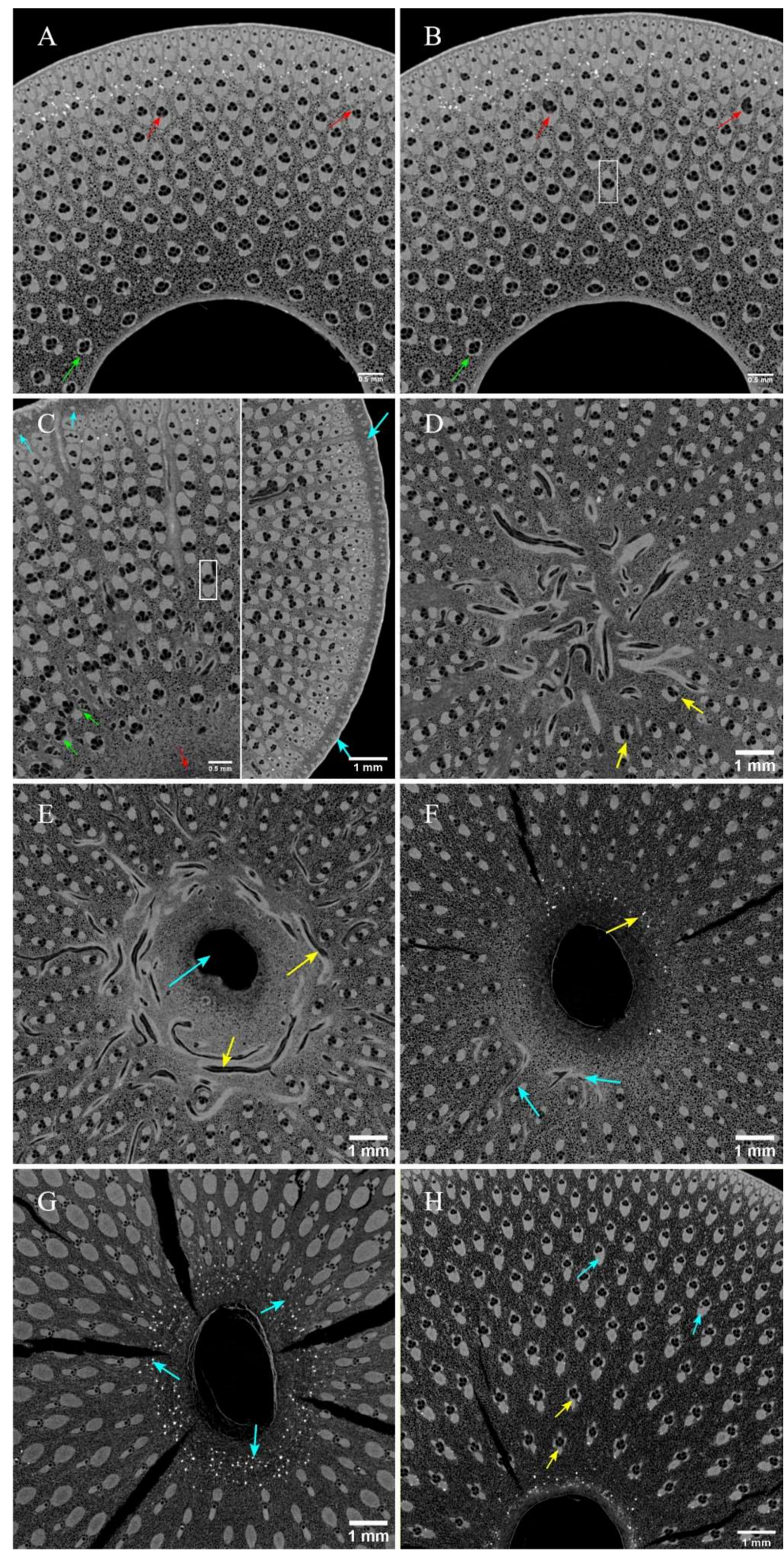

Figure 5. Specific picture of the cross-section of the bamboo node. Pictures $(\mathbf{A}-\mathbf{H})$ show partially enlarged illustrations of Pictures (a1-h1), respectively (picture $(\mathbf{B}, \mathbf{C})$, the size of the white wireframes of Pictures $(\mathbf{B}, \mathbf{C})$ was $\left.0.35 \times 0.8 \mathrm{~mm}^{2}\right)$. (A,B) Semi-open type vascular bundle (green arrow); conducting tissue before and after enlarged and deformed (red arrow). (C) Diaphragm (red arrow), irregularly shaped conducting tissue (green arrow), vascular bundles in the cortex (blue arrow). (D) Axial vascular bundles which changed orientation (yellow arrow). (E) Medullary cavity (blue arrow), transverse tubules (yellow arrow). (F) High-density materials (yellow arrow), transverse vascular bundle almost disappeared (blue arrow). (G) A large amount of high-density material (blue arrow). (H) Semi-open type vascular bundle (blue arrow), open type vascular bundle (yellow arrow). 


\subsubsection{Size and Quantity of Axial Vascular Bundles}

Table 1 shows the analysis of variance of the axial vascular bundle in the $\mu \mathrm{CT}$ transversal slice of the node with different heights in Q. tumidinoda. There was a significant difference between the average length and the mean width of axial vascular bundle. The average length of axial vascular bundles gradually increased from the lower end of the node to the middle of the nodal ridge and decreased toward the upper end of the nodal ridge. There was no significant difference of the mean length of axial vascular bundles in those slices which were between the end of the node and the lower end of the node and between the lower end of the sheath scar the upper end of the diaphragm. The maximum mean width of the axial vascular bundles presented in the middle of the nodal ridge. There was no significant difference of the mean width of axial vascular bundles in those slices which were between the end of the node and the middle of the diaphragm and between the upper end of the diaphragm and the lower end of the nodal ridge and between the middle of the nodal ridge and the upper end of the nodal ridge. The mean aspect ratio of the axial vascular bundle gradually increased from the lower end of the node to the lower end of the nodal ridge, and then decreased toward the upper end of the nodal ridge.

Table 1. The analysis of variance of the axial vascular bundles at different heights.

\begin{tabular}{ccccc}
\hline Sample & Slice Position & Mean Length (mm) & Mean Width (mm) & Mean Aspect Ratio \\
\hline Slice 339 & the end of the node & $0.41 \pm 0.12^{\mathrm{e}}$ & $0.26 \pm 0.09^{\mathrm{ih}}$ & $1.70 \pm 0.44$ \\
Slice 387 & the lower end of the node & $0.44 \pm 0.13^{\mathrm{e}}$ & $0.27 \pm 0.09^{\mathrm{hg}}$ & $1.73 \pm 0.46$ \\
Slice 579 & the lower end of the sheath scar & $0.55 \pm 0.14^{\mathrm{d}}$ & $0.28 \pm 0.06^{\mathrm{hg}}$ & $2.00 \pm 0.34$ \\
Slice 669 & the middle of the diaphragm & $0.56 \pm 0.12^{\mathrm{d}}$ & $0.27 \pm 0.05^{\mathrm{hg}}$ & $2.11 \pm 0.36$ \\
Slice 849 & the upper end of the diaphragm & $0.59 \pm 0.16^{\mathrm{d}}$ & $0.22^{\mathrm{b}} \pm 0.04^{\mathrm{i}}$ & $2.67 \pm 0.76$ \\
Slice 944 & the lower end of the nodal ridge & $0.75 \pm 0.14^{\mathrm{b}}$ & $0.24 \pm 0.04^{\mathrm{ih}}$ & $3.13 \pm 0.63$ \\
Slice 1129 & the middle of the nodal ridge & $0.85 \pm 0.30^{\mathrm{a}}$ & $0.32 \pm 0.11^{\mathrm{f}}$ & $2.71 \pm 0.86$ \\
Slice 1429 & the upper end of the nodal ridge & $0.70 \pm 0.30^{\mathrm{c}}$ & $0.31 \pm 0.11^{\mathrm{gf}}$ & $2.25 \pm 0.76$ \\
\hline
\end{tabular}

Note: there was no significant difference between the groups with the same alphabet in the table, and there was significant difference between the groups without the same alphabet (Duncan's test, at $5 \%$ level).

The variations in the number and frequency of axial vascular bundles in each slice of the bamboo node are shown in Figure 6. The changes in the number of axial vascular bundles in the cross-section of bamboo nodes were mainly caused by the branching of the vascular bundles into the diaphragm. The number of axial vascular bundles peaked at the lower end of the sheath scar and then decreased rapidly from the lower end of the sheath scar to the middle of the diaphragm, which was caused by the branching of the vascular bundles into the sheath scar [4]. The number of axial vascular bundles increased from the middle of the diaphragm to the upper end of the nodal ridge, which was related to the re-bending into the axial orientation of the transverse vascular bundles. No obvious changes were observed in the number of axial vascular bundles from the upper end of the nodal ridge to the upper end of the node. This was due to the lack of branching of the axial vascular bundles in the nodal ridge. The maximum and minimum frequencies of the axial vascular bundles at different heights of the node, respectively, appeared at the lower end of the node and in the middle of the nodal ridge, which was closely related to the size of the vascular bundles. 


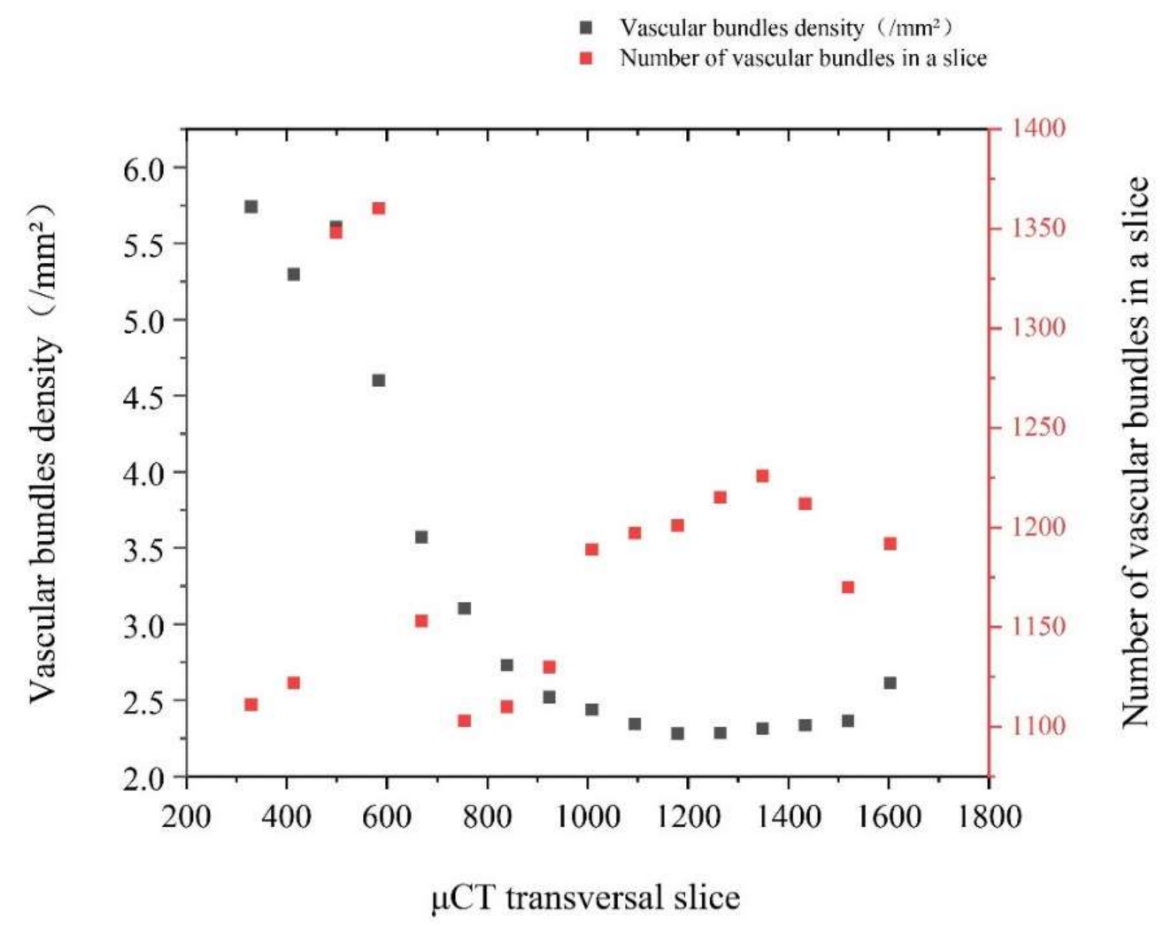

Figure 6. Variations of the number and frequency of axial vascular bundles at different heights of the bamboo node.

\subsubsection{Tissue Proportion}

The proportion of various tissues of the bamboo node and the variation trend of the number of vascular bundles were studied to better understand the structure of the bamboo node. The proportion of parenchyma, fibers, and conducting tissue in the node of Q. tumidinoda was $65.7 \%, 30.5 \%$, and $3.8 \%$, respectively (Figure 7). More parenchyma and less fibers and conducting tissues were present in the node than in the internode $[11,18,26]$. The proportion of different tissues changed with culm heights [17]. The proportion of the fibers was within the range of $19.7-40.1 \%$, and the maximum and minimum appeared in the slices 1185 and 898, which were located near the nodal ridge and at the upper end of the diaphragm, respectively. The parenchyma proportion ranged from $55.2 \%$ to $77.3 \%$, and the maximum and minimum appeared in the slices 949 and 535, which were located at the lower end of the nodal ridge and the lower end of the sheath scar, respectively. The proportion of conducting tissue was within $1-12.4 \%$, and the maximum and minimum appeared in the slices 549 and 1085, which were located at the lower end of the sheath scar and near the nodal ridge, respectively. The proportion of conducting tissues increased from the lower end of the node to the sheath scar, decreased toward the nodal ridge, and then leveled off until the upper end of the node. The fibers proportion showed the same changing trend as the conducting tissue from the lower end of the node to the lower end of the nodal ridge. The fibers proportion first increased and then decreased from the lower end of the nodal ridge to the top of the node, while the conducting tissue proportion showed no marked change. 
(a)

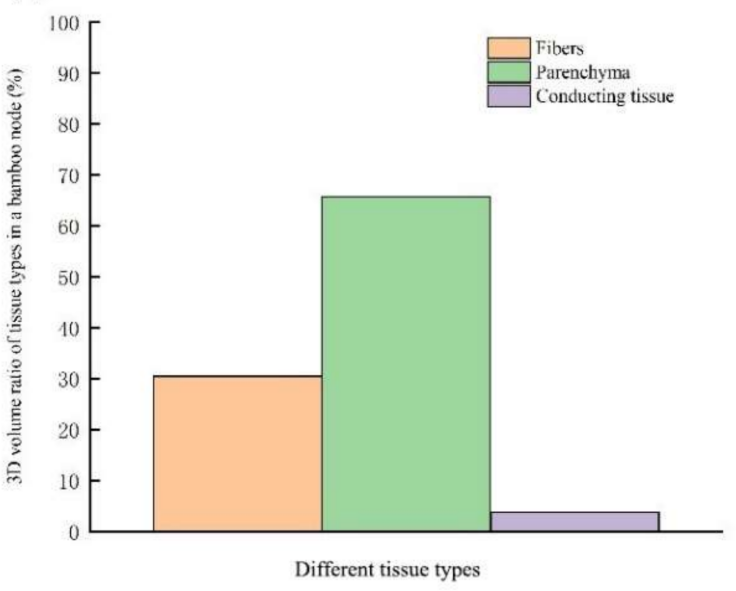

(b)

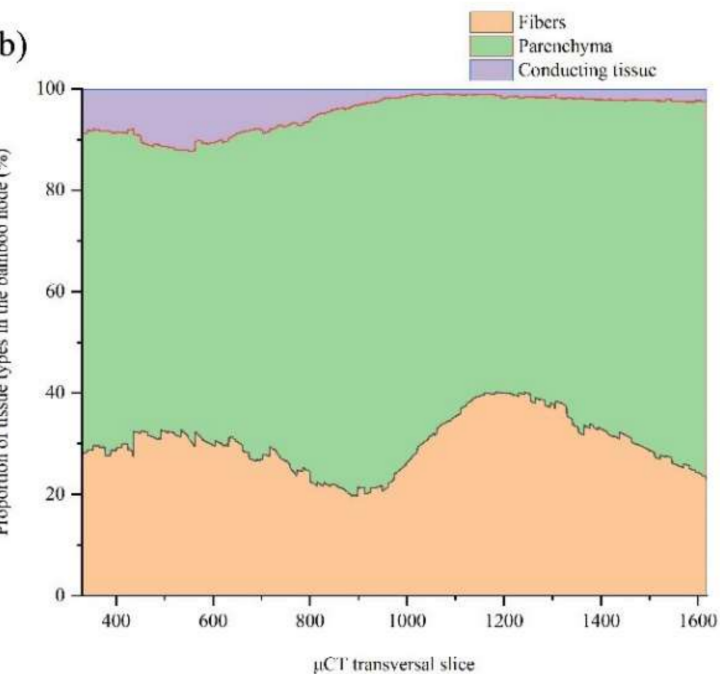

Figure 7. Tissue proportion of the bamboo node. (a) Proportions of different tissues in the node. (b) Distributions of tissue proportions in the node.

\subsection{Three-Dimensional Reconstruction of the Bamboo Node}

\subsubsection{Three-Dimensional Morphometry of the Conducting Tissue}

A topological and morphometrical study of the conducting tissue network of bamboo node is crucial to understand the anatomical features. It turns out that providing a skeleton of the conducting tissue is an efficient method to realize this target. A 3D skeleton of conducting tissue was obtained according to the method of Fouard et al. [21]. The generated color of the skeleton represented the relative thickness, which was obtained by computing the distance from the central axis to the nearest boundary, red indicated a larger thickness while blue meant a smaller thickness. In this way, it was possible for an observer to quantify the changes in regional conducting tissue thickness at a glance and throughout the entire node.

In the radial direction, the thickness of conducting tissue increased gradually from the outer layer to the inner layer of the node. The transverse conducting tissue with a higher thickness was distributed radially and entered into the diaphragm, where it was relatively concentrated and disordered. The conducting tissue with a smaller thickness was more widely distributed in the node (Figure 8a,c,e). In the tangential direction, the thickness of the conducting tissue of the node on the inflated side was smaller than that on the other side (Figure 8a,d). In the axial direction, the thickness of the conducting tissue in the node changed significantly. The thickness decreased from the lower end of node to the diaphragm and then gradually increased from the nodal ridge until a stable value was achieved (Figure $8 \mathrm{~b}, \mathrm{f}$ ).

The 3D view of the conducting tissue of the node revealed a slightly helical structure (Figure 8d), which was similar to the 3D microstructural reconstructions of the vascular bundle [17]. The axial conducting tissue curved outward in the outer layer of the bamboo culm from the upper end of the diaphragm to the nodal ridge, while it curved inward in the inner layer, which was similar to previous conclusions [4]. However, the orientation of the conducting tissue from the nodal ridge was opposite to that between the top of diaphragm and the nodal ridge (Figure 8 f). 


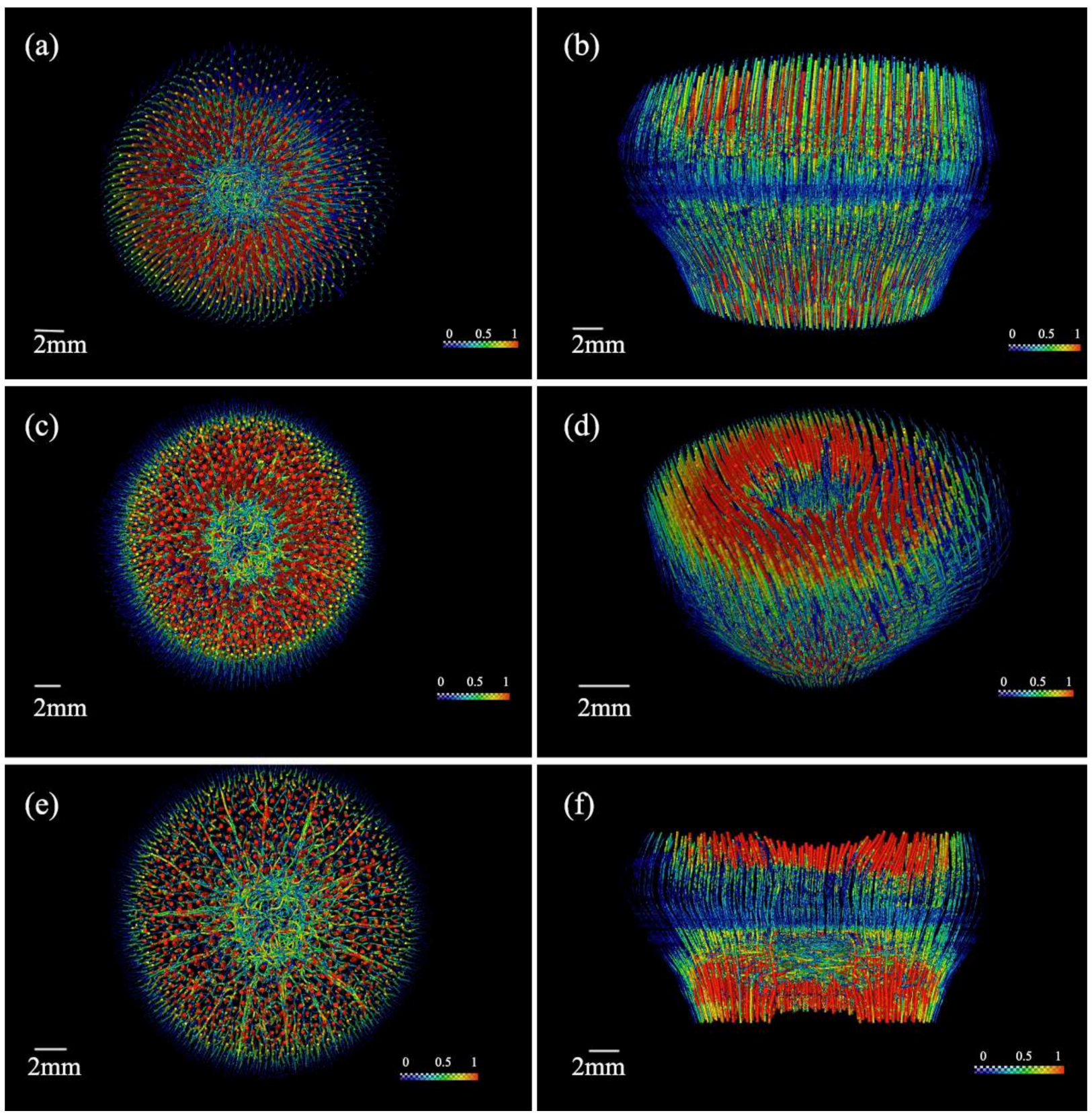

Figure 8. Three-dimensional skeleton conducting tissue in the node. (a) Top view. (b) Side view. (c) Bottom view. (d) 3D skeleton. (e) View of the transverse section. (f) View of the longitudinal section.

The volume of the conducting tissue in the diaphragm was approximately $144.38 \mathrm{~mm}^{3}$ (Figure 9a). This study screened the conducting tissue with the largest volume to clarify the volume of a single one. The maximum volume of the conducting tissue was $87 \mathrm{~mm}^{3}$, which accounted for $60.26 \%$ of the total volume of the conducting tissue. Most conducting tissues at the diaphragm were connected with each other (Figure 9b), while only few of them were not connected to the conducting tissue with the largest volume (Figure 9c). The highly connective conducting tissue made it impossible to trace its origin. 

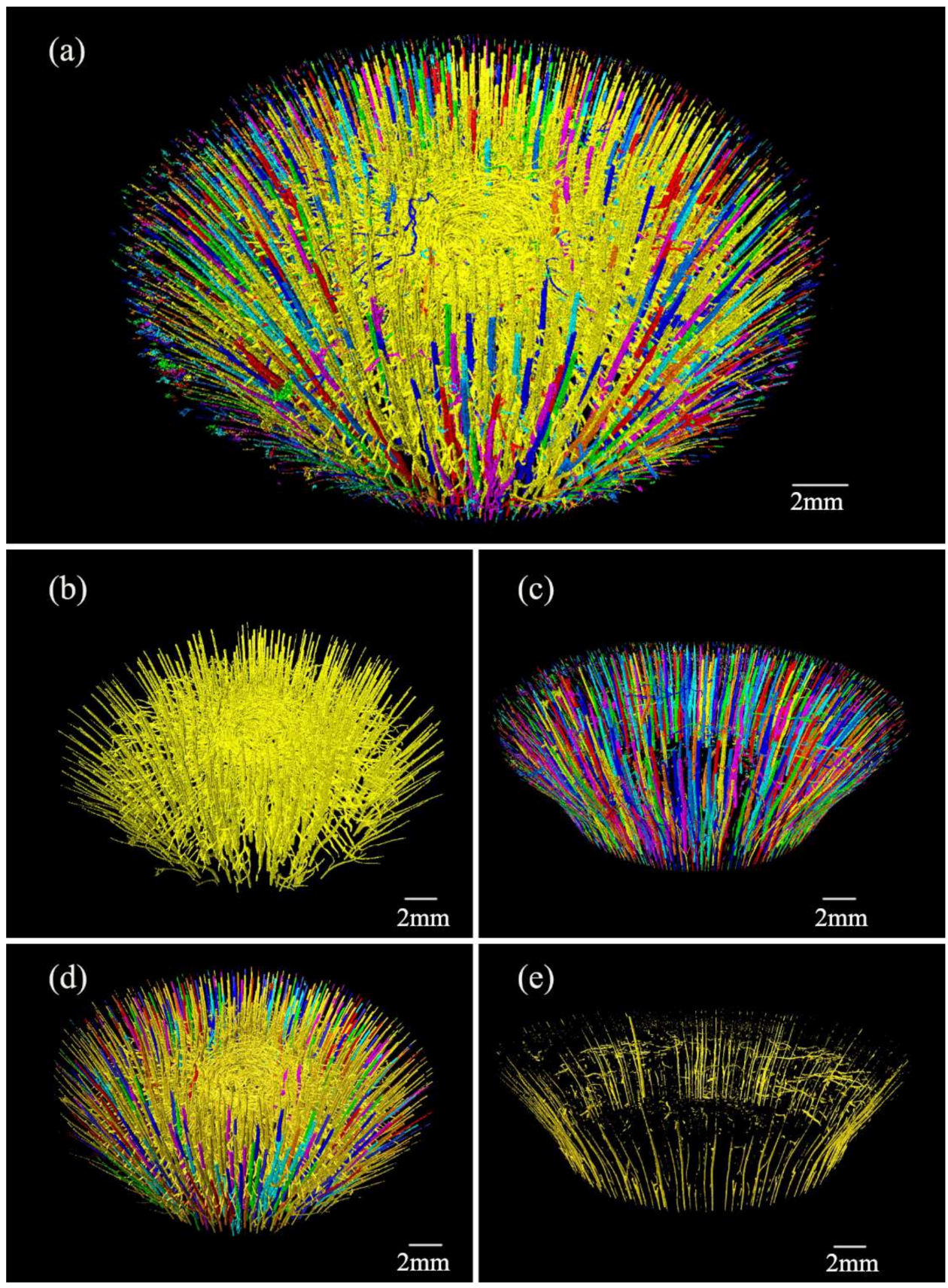

Figure 9. Conducting tissue in the diaphragm. (a) Three-dimensional model of the conducting tissue. (b) Conducting tissue with the largest volume. (c) Area except the conducting tissue with the largest volume. (d) Connected conducting tissue. (e) Unconnected conducting tissue.

This study respectively identified connected conducting tissues (Figure 9d) and the isolated one (Figure 9e) according to the pixel connectivity in digital $\mu \mathrm{CT}$ slices to evaluate the connectivity of the conducting tissues. The volume of the connected conducting tissue was $136.83 \mathrm{~mm}^{3}$, which accounted for $94.77 \%$ of the total conducting tissue volume. However, this connectivity value might be smaller than the actual value, which was due to the small pixels of the conducting tissue on the outer layer of the bamboo culm. This highly connected network structure improved resistance to embolism diffusion, reduced water flow resistance [27], and facilitated the tangential and axial transport of water and nutrients [13]. 


\subsubsection{Three-Dimensional Morphometry of the Fibers}

A 3D skeleton of the fibers in the node, as shown in Figure 10. The generated color of fibers was associated with the thickness of fibers, red indicates a larger thickness, while blue means thin. The thickness of the fibers at the bulge of the node was larger than that on the other side, the particularly developed fibers caused the enlarged node (Figure 10a). In addition, the bent fibers were thicker (Figure 10b), which was conducive to the storage of elastic energy [28]. In the radial direction, the thickness of the axial fibers gradually increased from the outer layer to the inner layer of the bamboo culm (Figure 10c). The transverse fibers were distributed radially and entangled with each other at the diaphragm (Figure 10e). This structure could improve the mechanical properties such as bending strength and splitting resistance $[2,16]$.
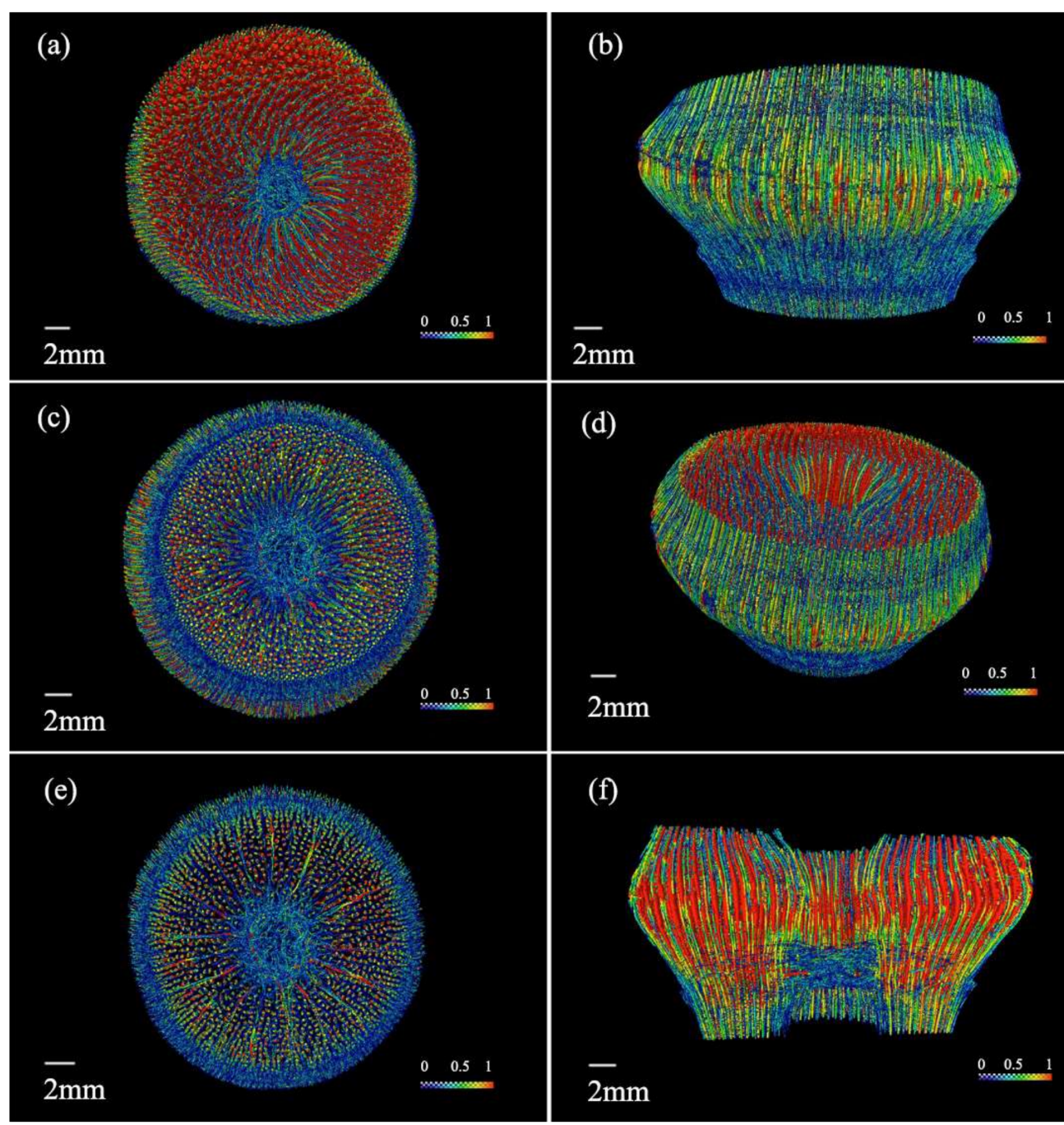

Figure 10. Three-dimensional skeleton of the fibers of the bamboo node (red indicates that the distance from the central axis of the fibers to the nearest boundary was relatively large, and blue indicates that the distance was relatively small). (a) Top view. (b) Side view. (c) Bottom view. (d) 3D skeleton. (e)View of the transverse section. (f) View of the longitudinal section.

The 3D distribution pattern of the fibers was similar to that of the conducting tissue. However, the fibers on the outer layer of the bamboo culm generated a large number of branches at the lower end of the sheath scar. After branching, some fibers continued to grow, while others stopped growing at the sheath scar (Figure 10b,d). This might be due to the closure of the vascular bundle when the intercalary meristem ceased its divisional activity and subsequent separation of the bamboo sheath from the culm [10]. The changing 
trend of fibers thickness was opposite to that of the conducting tissue. The thickness of the fibers increased from the diaphragm and reached the largest near the nodal ridge. The fibers thickness gradually decreased from the nodal ridge to stability (Figure 10d,f).

\section{Discussion}

In this study, X-ray microtomography combined with digital image processing technology was used to segment the complex nodal vascular system of monocots and present the 3D microstructural reconstructions of conducting tissue and fibers. The volume of connected conducting tissue accounted for $94.77 \%$, and the conducting tissues with the largest volume accounted for $60.26 \%$ of the total conducting tissue volume. Taken together, the results indicated that $\mu \mathrm{CT}$ was a proper tool to visualize and quantize the complex bamboo structure.

High-resolution $\mu \mathrm{CT}$, as a rapidly developing imaging technology, is being widely used in the research on the internal structure of plants [29-31]. Brodersen et al. [29] introduced microtomography (micro-CT) to quantitatively analyze the connectivity of the vessel network. Page et al. [30] obtained the connectivity of the branched xylem of Acacia using micro-CT. Previous published studies obtained insufficient information due to their small sample size. The inevitable problem of $\mu \mathrm{CT}$ application was that the resolution of the slice decreased as the sample size increased. In this study, in order to place the complete bamboo node within the scanning field of view, $\mu \mathrm{CT}$ slices were in low resolution, which caused suboptimal segmentation of the conducting tissues in the outer layer of the culm and resulted in the connectivity of this study being smaller than the actual value.

For $Q$. tumidinoda bamboo, the conducting tissue might be a whole network. The low connectivity of conducting tissue might be due to some characteristics not identified in the tissue segmentation process, or the seemingly separated conducting tissue in the node was connected with that in other bamboo nodes. To verify this hypothesis, systematic studies would require complete bamboo culm and higher-resolution equipment. Alternatively, micro-CT application in combination with other high-precision imaging technologies should be used, such that larger samples can be scanned at a higher resolution to improve the accuracy of structure recognition.

X-ray microtomography could also provide a new approach for bamboo penetration and mechanical analysis by obtaining $2 \mathrm{D}$ projections to transform volumetric data and performing numerical simulation or digital volume correlation analysis to visualize the corresponding displacement and strain field.

\section{Conclusions}

(1) X-ray microtomography was an ideal tool for visualizing and quantitatively analyzing the internal structure of the bamboo node. Furthermore, a large quantity of data of the quantitative indicators such as volume, area, tissue ratio, and connectivity of the bamboo node could be obtained with high speed by segmentation of $\mu \mathrm{CT}$ images combined with 3D visualization software such as AVIZO and ImageJ.

(2) The anatomical structure of Q. tumidinoda with enlarged node was acquired. It was the first time that the conducting tissue and the fibers from the completed node's vascular bundle were separated to observe its morphology, and the reconstruction of the skeleton made the morphology more intuitive. The 3D distribution patterns of the conducting tissue of the bamboo and those of the fibers were similar, but their thickness changed in the opposite pattern. The curved and branched conducting tissues in the bamboo node formed an intricate and highly connected 3D network structure, which was efficient at the transportation and circulation of nutrients inside the bamboo. 
Author Contributions: All the authors of the paper contributed to the research. Conceptualization and supervision, S.Y.; funding acquisition, S.Y. and X.L.; project administration, G.T. and J.M.; sample collection S.L. and L.S.; data curation, L.S. and Q.M.; investigation and data analysis, S.L. and L.S.; writing - original draft preparation, S.L., L.S. and S.Y.; writing — review and editing, S.L. and S.Y.; All authors have read and agreed to the published version of the manuscript.

Funding: This work was supported by the Fundamental Research Funds of National Natural Science Foundation of China (grant nos. 31670565) and the National Science and Technology Support Plan (grant nos. 2015 BAD04 B03).

Institutional Review Board Statement: Not applicable.

Informed Consent Statement: Not applicable.

Data Availability Statement: Not applicable.

Acknowledgments: We are grateful to Wenyuan Dong of Southwest Forestry University for confirming the bamboo age during the sampling process and increasing understanding of this bamboo. Thanks to the Forestry and Grassland Administration of the Daguan County, Zhaotong City, Yunnan Province for providing experimental materials, and thanks to Thermo Fisher Scientific (China) Co., Ltd., Shanghai, China for providing guidance during experimental and data processing.

Conflicts of Interest: The authors declare no conflict of interest.

\section{References}

1. Liu, S.; Tong, Z.; Tang, Z.; Yang, L.; Zhang, Z. Bionic design modification of non-convex multi-corner thin-walled columns for improving energy absorption through adding bulkheads. Thin Wall Struct. 2015, 88, 70-81. [CrossRef]

2. Zou, M.; Xu, S.; Wei, C.; Wang, H.; Liu, Z. A bionic method for the crashworthiness design of thin-walled structures inspired by bamboo. Thin Wall Struct. 2016, 101, 222-230. [CrossRef]

3. Wang, F.; Shao, Z.; Wu, Y.; Wu, D. The Toughness Contribution of Bamboo Node to the Mode I Interlaminar Fracture Toughness of Bamboo. Wood Sci. Technol. 2014, 48, 1257-1268. [CrossRef]

4. $\quad$ Ding, Y.L.; Liese, W. On the nodal structure of bamboo. Bamboo Res. 1995, 14, 24-32.

5. Burgert, I. Exploring the Micromechanical Design of Plant Cell Walls. Am. J. Bot. 2006, 93, 1391-1401. [CrossRef]

6. Wansi, F.; Zhangrong, Z.; Wang, H.; Jianbo, Z. Research on finite element model for parallel to bamboo culms axial shear. Appl. Mech. Mater. 2014, 477, 986-989.

7. Ghysels, P.; Samaey, G.; Tijskens, B.; Liedekerke, P.V.; Ramon, H.; Roose, D. Multi-scale simulation of plant tissue deformation using a model for individual cell mechanics. Phys. Biol. 2009, 6, 016009. [CrossRef]

8. Lee, C.L.; Chin, T.C. Anatomical Studies Of Some Chinese Bamboos. J. Integr. Plant Biol. 1960, 9, 76-97.

9. Ding, Y.L.; Fang, R.W.; Huang, J.S. Development and Ultrastructure of the Phloem Ganglion in Bamboo Node. Acta Bot. Sin. 2000, $42,1009-1013$.

10. Xiong, W.Y.; Qiao, S.Y.; Li, Y.F. The Anatomical Structure Of Culms Of Phyllostachys pubescens Mazel ex H.de Lehaie. Acta Bot. Sin. 1980, 22, 343-348.

11. Grosser, D.; Liese, W. On the Anatomy of Asian Bamboos, with Special Reference to Their Vascular Bundles. Wood Sci. Technol. 1971, 5, 290-312. [CrossRef]

12. Xiong, W.Y.; Ding, Z.F.; Li, Y.F. Intercalary Meristem And Internodal Elongation Of Bamboo Plants. Sci. Silvae Sin. 1980, 16, 81-89.

13. Peng, G.Y.; Jiang, Z.H.; Liu, X.E.; Fei, B.H.; Yang, S.M. Detection of complex vascular system in bamboo node by X-ray $\mu$ ct imaging technique. Holzforschung 2014, 68, 223-227. [CrossRef]

14. Xiang, E.; Yang, S.; Cao, C.; Liu, X.; Peng, G.; Shang, L.; Tian, G.; Ma, Q.; Ma, J. Visualizing complex anatomical structure in bamboo nodes based on x-ray microtomography. J. Renew. Mater. 2021, 9, 1531-1540. [CrossRef]

15. Huang, P.; Chang, W.S.; Ansell, M.P.; Chew, Y.; Shea, A. Density distribution profile for internodes and nodes of phyllostachys edulis (moso bamboo) by computer tomography scanning. Constr. Build. Mater. 2015, 93, 197-204. [CrossRef]

16. Huang, P.; Chang, W.S.; Ansell, M.P.; John, C.; Shea, A. Porosity estimation of phyllostachys edulis (moso bamboo) by computed tomography and backscattered electron imaging. J. Wood Sci. Technol. 2017, 51, 11-27. [CrossRef]

17. Palombini, F.L.; Kindlein, W.; De Oliveira, B.F.; Ernesto, D.A.M.J. Bionics and design: $3 d$ microstructural characterization and numerical analysis of bamboo based on x-ray microtomography. Mater. Charact. 2016, 120, 357-368. [CrossRef]

18. Palombini, F.L.; Nogueira, F.M.; Junior, K.W.; Paciornik, S.; Mariath, J.E.D.A.; Olivwira, B.F.D. Biomimetic Systems and Design in the 3D Characterization of the Complex Vascular System of Bamboo Node Based on X-Ray Microtomography and Finite Element Analysis. J. Mater. Res. 2020, 35, 842-854. [CrossRef]

19. Palombini, F.L.; Lautert, E.L.; Mariath, J.; Oliveira, B. Combining numerical models and discretizing methods in the analysis of bamboo parenchyma using finite element analysis based on x-ray microtomography. Wood Sci. Technol. 2020, 54, 161-186. [CrossRef] 
20. Ignacio, A.C.; Verena, K.; Curtis, R.; Eliceiri, K.W.; Johannes, S.; Albert, C.; Seung, H.S. Trainable weka segmentation: A machine learning tool for microscopy pixel classification. Bioinformatics. Bioinformatics 2017, 33, 2424-2426.

21. Fouard, C.; Malandain, G.; Prohaska, S.; Westerhoff, M. Blockwise processing applied to brain microvascular network study. IEEE Trans. Med. Imaging 2006, 25, 1319-1328. [CrossRef]

22. Hege, H.C.; Stalling, D.; Seebass, M.; Zockler, M. A Generalized Marching Cubes Algorithm Based on Non-Binary Classifications; Preprint SC 97-05; ZIB: Berlin, Germany, 1997.

23. Wen, T.H.; Zhou, W.W. A Report on the Anatomy of the Vascular Bundle of Bamboos from China. Bamboo Res. 1984, 3, 1-21.

24. Peng, G.Y. Study on Detection of Structure Characteristics for Wood and Bamboo Using Computed Tomography. Ph.D. Thesis, Chinese Academy of Forestry, Beijing, China, 2010.

25. Robischon, M.; Du, J.; Groover, M.A. The populus class iii hd zip, poprevoluta, influences cambium initiation and patterning of woody stems. Plant Physiol. 2011, 155, 1214-1225. [CrossRef]

26. Marinho, N.P.; Nisgoski, S.; Muñiz, G.I.B.d. Avaliação das dimensões das fibras de colmos de bambu, dendrocalamus giganteus (wall) munro, em diferentes idades. Cienc. Florest. 2014, 24, 251-256. [CrossRef]

27. Mrad, A.; Johnson, D.M.; Love, D.M.; Domec, J.C. The Roles of Conduit Redundancy and Connectivity in Xylem Hydraulic Functions. New Phytol. 2021, 231, 996-1007. [CrossRef]

28. Wu, W.; Xia, R. 3D Microstructure Reconstruction of Bamboo Fiber and Parenchyma Cell. J. Nat. Fibers 2019, 18, 1119-1127. [CrossRef]

29. Brodersen, C.R.; Lee, E.F.; Choat, B.; Jansen, S.; Matthews, M.A. Automated analysis of three-dimensional xylem networks using high-resolution computed tomography. New Phytol. 2011, 191, 1168-1179. [CrossRef]

30. Page, G.; Liu, J.; Grierson, P.F. Three-dimensional xylem networks and phyllode properties of co-occurring acacia. J. Plant Cell Environ. 2011, 34, 2149-2158. [CrossRef]

31. Bulcke, J.V.D.; Boone, M.A.; Dhaene, J.; Loo, D.V.; Hoorebeke, L.V.; Boone, M.N.; Wyffels, F.; Beeckman, H.; Acker, J.V.; Mil, T.D. Advanced x-ray ct scanning can boost tree-ring research for earth-system sciences. Ann. Bot-Lond. 2019, 124, 837-847. [CrossRef] [PubMed] 